\title{
Cognitive function of young male tennis players and non-athletes
}

\author{
Petra Pačesová*, Pavel Šmela, Stanislav Kraček, Klaudia Kukurová, and Lucia Plevková
}

Faculty of Physical Education and Sports, Comenius University in Bratislava, Bratislava, Slovakia

Copyright: (C) 2018 P. Pačesová et al. This is an open access article licensed under the Creative Commons Attribution License (http://creativecommons.org/licenses/by/4.0/).

\begin{abstract}
Background: Cognitive functions can be defined as the ability of individuals to participate, recognize and plan responses to external and internal impulses. We can define attention as the active focus of our consciousness and the ability to concentrate mental functions on a certain activity. In competitive tennis, attention, especially conscious attention which is controlled by cognitive and volitional processes plays a significant role. Objective: The aim of this study was to assess differences in cognitive functions between tennis players and non-athletic adolescents. Methods: The research sample consisted of 98 subjects: 44 tennis players (age $18.11 \pm 1.35$ years) and 54 nonathletic adolescents (age $18.04 \pm 1.33$ years). The level of cognitive functions was investigated using the standardized neuropsychological cognitive Stroop test. Results: The tennis players had higher cognitive function scores compared to the non-athletes in two of the three segments of the Stroop test. There was no significant difference between the groups in the simplest segment of the Stroop test (segment T). However, a significant difference ( $p=.028 ; d=0.45$ ) was found between the tennis players and non-athletes in segment $\mathrm{S}$ of the Stroop test and in segment B, the most difficult segment of the test, the difference between research groups was also significant ( $p=.002 ; d=0.63$ ). Conclusion: Based on acquired data, we can see a difference between athletes and non-athletes in cognitive functions such as cognition inhibitory control, concentration of attention, conscious and selective attention. However, the differences have only been demonstrated in moderate difficulty and most difficulty segment, in the simplest segment we have not found difference between athletes and non-athletes.
\end{abstract}

Keywords: Stroop test, inhibitory control, attention, athletes, non-athletes

\section{Introduction}

Cognitive functions can be defined as the ability of individuals to participate, recognize and plan responses to external and internal impulses; they also include executive functions which include the ability to plan and schedule activities, to focus on information related to specific tasks and to carry out several activities or skills simultaneously (Vařeková \& Dad’ová, 2014; Ward, 2006). Core executive functions include inhibition response and interference control (selective attention and cognitive inhibition), working memory, and cognitive flexibility (Diamond, 2013). Interference control refers to the ability to selectively focus on certain information while ignoring distracting information (Ma et al., 2018). Attention is an active focus of

\footnotetext{
* Address for correspondence: Petra Pačesová, Department of Sports Educology and Sports Humanistic, Faculty of Physical Education and Sports, Comenius University in Bratislava, nábr. arm. gen. L Svobodu 9, 81469 Bratislava, Slovakia. E-mail: petra.pacesova@uniba.sk
}

our consciousness, the ability to concentrate mental functions on a certain activity. This includes the ability to pay attention to significant stimuli and exclude insignificant stimuli (Höschl, Libiger, \& Švestka, 2002). According to Czajkowski (1996), attention is a cognitive function which may be conscious or unconscious, and is directed toward a certain object, action, activity, situation or phenomenon which determines the quality and effectiveness of perception and decision-making.

The characteristics of attention differ according to age. Selectiveness and the ability to shift attention develop over time and should be relatively strong during adolescence. During puberty and adolescence, all the characteristics of attention should be developed, especially concentration, intensity and permanence (Šlédr, 2000; Weiner, Lerner, Easterbrooks, \& Mistry, 2003). Adolescents can better control their attention and employ various strategies to focus attention in a simpler and more sustainable way. In late adolescence cognitive functions are improved, as well as the ability to control attention (Vágnerová, 2005). 
As Vestberg, Gustafson, Maurex, Ingvar, and Petrovic (2012) claim, more focus has recently been directed toward cognitive functions important for different sports. Pesce (2012) in her review suggested that motor cognitive training has the potential to capitalize on the cognitive benefits of participation in physically demanding and mentally engaging activities.

Exercise through participation in sports rather than simple activities might be useful for supporting the development of executive functions. Although the effects of specific sports activities on executive functions are still uncertain (Ishihara, Sugasawa, Matsuda, $\&$ Mizuno, 2016), many cross-sectional and longitudinal intervention studies have shown a relationship between a sports activity and cognitive function (Alesi, Bianco, Luppine, Palma, \& Pepi, 2016; Davis et al., 2007; Huijgen et al., 2015; Ishihara, Sugasawa, Matsuda, \& Mizuno, 2017; Lundgren, Högman, Näslund, \& Parling, 2016; Scudder et al., 2014; Vestberg et al., 2012). From the point of view of the level of sports activity, Heppe, Kohler, Fleddermann, and Zentgraf (2016) found that elite athletes (playing different team sports), performed better in sustained attention tests, compared to recreational athletes. These findings show that diverse types of physical activity, such as volleyball, soccer, tennis or ice hockey, can improve cognitive functions in children and adolescents.

Fernandez-Fernandez, Sanz-Rivas, and MendezVillanueva (2009) claim that playing tennis requires cognitive engagement and specific strategic behaviours, superior reaction time, anticipation, decision making capacities, and sensorimotor learning. Furthermore, tennis is associated with the development of three foundational aspects of executive function: inhibitory control, working memory and cognitive flexibility (Fernandez-Fernandez et al., 2009).

Frequent participation in tennis is related to better inhibitory control and working memory, while longer experience with tennis is associated with better cognitive flexibility (Ishihara et al., 2017). We can also consider the effects of physical activity on cognitive functions based on the findings of Jansen, Ellinger, and Lehmann (2018), who determined a higher level of cognitive functions of adolescents attending sports classes compared to those who did not attend sports classes. There appears to be empirical evidence indicating that regular physical activity and sports improve cognitive function.

In competitive tennis, attention plays a significant role, especially conscious attention (Crespo \& Milley, 2001). Focusing attention on the trajectory of the ball is a constant task in tennis. Higher concentration and intensity of attention allows tennis players to perceive real external activity such as the movement of the opponent on the court and the flight of the ball, in relatively slower motion (Šlédr, 2000).

Concentrating attention is one of the most important psychological abilities for success in competitive tennis (Crespo \& Milley, 2001). Authors define it as concentration on selected elements which are significant for the game, while insufficient concentration suggests concentration on non-essential impulses. Thus, a player must precisely know which aspects of the game are relevant for the match in terms of various game situations (Crespo \& Milley, 2001).

Based on these findings, we can assume that the requirements for concentration of attention, cognitive inhibitory control and selectiveness on relevant impulses grow with athletes and will be at higher level in comparison with the non-athletic population. Thus, the aim of this study is to evaluate the differences in cognitive functions between healthy male athletes and non-athletes. The findings in this area of knowledge should be confirmed and the question of whether it is possible to improve cognitive functions without a deliberate cognitive training programme, but through regular physical activity in which cognitive functions are applied should be answered.

\section{Methods}

\section{Participants}

The research group was comprised of 98 healthy male subjects from 16 to 20 years of age. The athletic group was comprised of 44 male tennis players (age $18.11 \pm 1.35$ years) from the Bratislava Tennis Academy who underwent 9 hours of tennis training per week on average. All of them were elite players. Elite sport assumes the highest sport performance and provides economic background or state representation for athletes (Kučera \& Dylevský, 1999). The group of non-athletic individuals was comprised by 54 males (age $18.04 \pm 1.33$ years) who were students of schools in Bratislava and who did not engage in any other physical activity aside from school physical education lessons. None of these participants had previously participated in a cognitive training programme or taken the Stroop test. Furthermore, none of them had ever received special needs education due to a cognitive function or attention disorder. The study design was approved by the Ethics Committee of the Faculty of Physical Education and Sport of Comenius University. Data were collected with the informed consent of the subjects or their legal representatives. 


\section{Measurement}

The Stroop test is oriented on detecting informationprocessing speed, selective attention in the visual system, inhibitory control, which is significantly applied in this test and manifested so that similar psychological elements which are stored in the memory have a mutually disturbing effect on each other, and which in essence is the fundamental cause for problems when recalling them (Plháková, 2003; Stroop, 1935).

The Victoria version (VST) of the Neuro-psychological Stroop Colour-Word Test, which is comprised of three models with $21.5 \times 14 \mathrm{~cm}$ dimensions with six lines of four items in each line, was used to determine the level of cognitive functions. The spacing between the lines was $1 \mathrm{~cm}$. In the first $T$ segment, the participant was expected to name the colours of dots as fast as possible. In the second $\mathrm{S}$ segment, the dots were replaced by ordinary words in small print. The individual had to identify the colour in which the word was printed regardless of its content. In the third and most difficult segment $\mathrm{B}$, the colour stimuli were the names of colours in small print, but the colour of the print never corresponded to the name of the colour. Individual segments of this test were arranged according to difficulty and presented in the same order T, S, B. The examined individual was instructed to read or say the names of the colours as fast as possible. The timing began immediately after the instructions were given (Stroop, 1935).

\section{Statistical analysis}

Statistical comparison was performed using SPSS software (Version 23 for Windows; IBM, Armonk, NY, USA). The Shapiro-Wilk test confirmed the normality of the data. We used the independent sample $t$-test to process the research data. The effect size of the differences was assessed by Cohen's $d$ (Cohen, 1988). The magnitude of the $d$ coefficient was evaluated in the following ranges: $d \geq 0.8$ (large effect), $d \geq 0.5$ and $<0.8$ (medium effect), and $d \geq 0.2$ and $<0.5$ (small effect).

\section{Results}

We compared the groups of athletes (tennis players) and non-athletes in terms of individual segments of the Stroop test and presented the results graphically via boxplot. The results of the Stroop test segments are from the simplest segment to the most difficult.

Part T of the Stroop test is the simplest segment and is oriented on the simple naming of the colours of the dots. These results indicated that the difference in the mean values of the group of tennis players and nonathletes was not statistically significant $(t(96)=-0.99$, $p=.326, d=0.20)$. The mean value of the group of non-athletic participants was $13.05 \pm 1.72 \mathrm{~s}$, while the mean value of the group of tennis players was $12.71 \pm 1.72 \mathrm{~s}$.

Part S of the Stroop test is of moderate difficulty because of the inhibitory control and the increasing requirements for conscious and selective attention and concentration of attention. The participant is expected to name the colour in which the subjective word is printed as fast as possible regardless of its content. There was significant difference between tennis players and non-athletic participants; the mean value among the tennis players was $15.03 \pm 1.50 \mathrm{~s}$, while the mean value among the non-athletic participants was $15.71 \pm 1.48 \mathrm{~s}(t(96)=-2.29, p=.028, d=0.45)$.

In part B, the most difficult segment of the Stroop test, the subject is expected to name the colour as fast as possible regardless of the name of the colour which the word designates. Thus, the inhibitory control and interference effect is the most significant. The difference between group of tennis players and non-athletic participants was statistically significant $(t(96)=-3.16$, $p=.002, d=0.63$ ); the mean value among the tennis players was $24.70 \pm 3.39 \mathrm{~s}$, while the mean value among the nonathletic participants was $26.73 \pm 3.04 \mathrm{~s}$.

\section{Discussion}

In evaluating the level of cognitive functions, the tennis players demonstrated a significantly higher level of cognitive functions in comparison with the nonathletic participants in two of the three segments of the Stroop test. This was possibly due to task difficulty. Athletes performed significantly better in the moderately difficult and the most difficult segments. Based on our results, we can state that healthy male athletes show a higher level of cognitive functions compared to healthy male non-athletes. As previously noted, the Stroop test places high requirements on selective attention, inhibitory control and executive functions (as a sub-category of cognitive functions), while also focusing on the complex cognitive area which in practice represents increased requirements for resistance to short-term mental burdens. As a result, we can consider the Stroop test to be a type of experimental stressor, similar to the findings of Liston, McEwen, and Casey (2009) and Daniel (1983). Therefore, we can assume that specific situations on the court can represent a certain type of stress to which tennis players are better adapted and which allows them to better handle the conditions of the experimental stressor in the form of the test, although it has a different form. In addition, Ishihara et al. (2017) state that tennis is a cognitively 
engaging physical activity and requires executive, function-dependent cognition (e.g., decision-making, strategic behaviour). These characteristics might have contributed to facilitating executive functions. According to the authors, we can suppose that cognitively engaging physical activities, such as tennis, have beneficial effects on executive function development.

As Kutlík and Člko (2013) state, the issues related to cognitive functions within younger subjects have only been researched in the last decade. Our findings correspond with some findings in the area of cognitive functions and physical activity. The research of Kutlík and Člko (2013) has shown a statistically significant impact of physical activity on the cognitive functions of children in testing that was targeted on memory, attention and executive functions. Martin et al. (2018) have also reported reliable evidence for improving cognitive executive function by physical activity-only interventions. We can assume that the reason for such findings is that executive functions, which are also cognitive functions, have been found to be more sensitive to physical activity than other types of cognitive functions (Best, 2010).

Moreover, as Best (2010) states, improved executive function after participation in physical activity might depend on the type of physical activity. In this context, Ishihara et al. (2017) state that different physical activities require different demands on cognitive functions. The authors also assume that executive function is moderated by sports type. It means that open skill sports such as tennis require the coordination of complex bodily movements and adaptation to continually changing task demands.

In the research by Crova et al. (2014) with a group of tennis players, the authors found that tennis interventions supported executive function development. Alves et al. (2013) conducted research to examine the relationship between sports expertise and perceptual and cognitive functions. The participants performed a cognitive battery of tests of inhibitory control, working memory, and visual-spatial attention. Athletes showed superior performance speed on three tasks (two inhibitory control tasks and one visual-spatial attentional processing task). Moreover, it seems, that cognitive functions are predicted by different variables. According to the findings of Marchetti et al. (2015), working memory was predicted by physical fitness, while inhibition control was predicted by game skill, physical fitness and the response orientation ability of adolescents. This finding can be discussed from the point of view of our results, i.e., athletes playing tennis (compared to non-athletes), showed a higher level of cognitive functions measured by the Stroop test, including inhibition control.
The research findings of Ishihara et al. (2017) show that more frequent tennis play was associated with better working memory (after controlling for age, gender, BMI, and tennis experience). Furthermore, longer tennis experience was related to better cognitive flexibility in males. They stated that although the development of inhibitory control and cognitive flexibility is slower in males than in females, the associations between tennis and inhibitory control and cognitive flexibility appear to be greater in males than in females. Booth et al. (2013) tested attention as a cognitive function and physical activity. Their findings suggested that physical activity may be beneficial for attention processes in adolescence, especially in males. This finding regarding gender differences seems to be important. Our research focused on the level of cognitive functions in a group of male and findings show significant improving of cognitive functions in athletes as well.

Voss, Kramer, Basak, Prakash, and Roberts (2010) found in their meta analytic review that athletes performed better than non-athletes in cognitive functions (processing speed and a category of varied attentional paradigms), and athletes from interceptive sport types, especially males, scored the best results. According to the authors, tennis is an interceptive sport type. Moreover, sport type was found to be a moderator for the sport-cognition relationship; their findings showed that interceptive sports (e.g., tennis) have shown the best results.

Generally, our findings correspond with other findings in this area of knowledge which refer to the effects of various kinds of physical activity (e.g., hockey, soccer, tennis or volleyball) on cognitive functions.

Also, Vařeková and Dadová (2014) claim that the potential of physical activity supports cognitive functions with healthy children, adults as well as individuals with disabilities.

Despite this study's interesting findings in the area of cognitive functions on the difference between male athletes and non-athletes, it has several limitations that should be acknowledged. Firstly, the size of the research group of athletes and non-athletes of our research was relatively small. We assume that the specificity which tennis has in relation to cognitive functions (e.g., concentration on the opponent's movements, concentration on the flight and landing of a tennis ball) leads to the higher cognitive functions of tennis players in comparison to that of the general population. However, we cannot confirm this statement without further research. Since the adolescent participants in our research were all tennis players, we suggest carrying out research to investigate the impact and relationship between requirements for cognitive functions imposed on tennis players during the match 
and the level of their cognitive functions, considering variables such as age, training age, level of sport activity, BMI index and gender. These findings may reveal the extent to which a specific sports activity such as tennis can influence cognitive functions. Regardless of the research limitations, we can say that adolescents participating in sports activities have better cognitive functions in comparison to adolescents who do not participate in any sports activity.

\section{Conclusion}

The athletes performed better in two of three segments of the Stroop test - segment S (moderate difficulty) and segment B (the most difficulty), because of the cognition inhibitory control and the increasing requirements for conscious and selective attention and concentration of attention. Based on the acquired data, regular physical activity might have beneficial effects on cognitive functions such as selective attention, inhibitory control and executive function in healthy male adolescents.

\section{Acknowledgments}

The authors wish to thank all of the tennis players for participating in this study.

\section{Conflict of interest}

There were no conflicts of interest.

\section{References}

Alesi, M., Bianco, A., Luppine, G., Palma, A., \& Pepi, A. (2016). Improving children's coordinative skills and executive functions: The effects of a football exercise program. Perceptual and Motor Skills, 122, 27-46.

Alves, H., Voss, M. W., Boot, W. R., Deslandes, A., Cossich, V., Salles, J. I., \& Kramer, A. F. (2013). Perceptualcognitive expertise in elite volleyball players. Frontiers in Psychology, 4, 36.

Best, J. R. (2010). Effects of physical activity on children's executive function: Contributions of experimental research on aerobic exercise. Developmental Review, 30, 331-351.

Booth, J. N., Tomporowski, P. D., Boyle, J. M., Ness, A. R., Joinson, C., Leary, S. D., \& Reily, J. J. (2013). Associations between executive attention and objectively measured physical activity in adolescence: Findings from ALSPAC, a UK cohort. Mental Health and Physical Activity, 6, 212-219.

Cohen, J. (1988). Statistical power analysis for the behavioural sciences (2nd ed.). Hillsdale, NJ: Erlbaum.
Crespo, M., \& Milley, D. (2001). Tenisový trenérský manuál 2. stupně (pro tenisové trenéry) [Manual for tennis training, 2nd degree (for tennis coaches)]. Olomouc, Czech Republic: Palacký University Olomouc.

Crova, C., Struzzolino, I., Marchetti, R., Masci, I., Vannozzi, G., Forte, R., \& Pesce, C. (2014). Cognitively challenging physical activity benefits executive function in overweight children. Journal of Sports Sciences, 32, 201-211.

Czajkowski, Z. (1996). Psychologia sprzymierzeńcem trenera [Psychology - the coach's ally]. Warsaw, Poland: Centralny Ośrodek Sportu.

Daniel, J. (1983). Stroopov test [Stroop Test]. Bratislava, Czechoslovakia: Psychodiagnostické a didaktické testy.

Davis, C. L., Tomporowski, P. D., Boyle, C. A., Waller, J. L., Miller, P. H., Naglieri, J. A., \& Gregoski, M. (2007). Effects of aerobic exercise on overweight children's cognitive functioning: A randomized controlled trial. Research Quarterly for Exercise and Sport, 78, 510-519.

Diamond, A. (2013). Executive functions. Annual Review of Psychology, 64, 135-168.

Fernandez-Fernandez, J., Sanz-Rivas, D., \& Mendez-Villanueva, A. (2009). A review of the activity profile and physiological demands of tennis match play. Strength and Conditioning Journal, 31, 15-26.

Heppe, H., Kohler, A., Fleddermann, M. T., \& Zentgraf, K. (2016). The relationship between expertise in sports, visuospatial, and basic cognitive skills. Frontiers in Psycholology, 7, 904.

Höschl, C., Libiger, J., \& Švestka, J. (Eds.). (2002). Psychiatrie [Psychiatry]. Prague, Czech Republic: Tigis.

Huijgen, B. C. H., Leemhuis, S., Kok, N. M., Verburgh, L., Oosterlaan, J., Elferink-Gemser, M. T., \& Visscher, C. (2015). Cognitive functions in elite and sub-elite youth soccer players aged 13 to 17 years. PLoS ONE, 10(12), e0144580.

Ishihara, T., Sugasawa, S., Matsuda, Y., \& Mizuno, M. (2016). Improved executive functions in 6-12-year-old children following cognitively engaging tennis lessons. Journal of Sports Sciences, 35, 2014-2020.

Ishihara, T., Sugasawa, S., Matsuda, Y., \& Mizuno, M. (2017). Relationship of tennis play to executive function in children and adolescents. European Journal of Sport Science, 17, 1074-1083.

Jansen, P., Ellinger, J., \& Lehmann, J. (2018). Increased physical education at school improves the visual-spatial cognition during adolescence. Educational Psychology. Advance online publication. doi:10.1080/01443410.2018. 1457777

Kučera, M., \& Dylevský, I. (1999). Sportovní medicína [Sport medicine]. Prague, Czech Republic: Grada.

Kutlík, D., \& Čelko, S. (2013). Pohybová, najmä vytrvalostná aktivita a jej vplyv na psychické funkcie a stavy detí [Physical, especially endurance activity and its effect on mental function and status of children]. Tělesná výchova a sport mládeže, 79(6), 41-47.

Liston, C., McEwen, B. S., \& Casey, B. J. (2009). Psychosocial stress reversibly disrupts prefrontal processing and attentional control. Proceedings of the National Academy of Sciences of the United States of America, 106, 912-917.

Lundgren, T., Högman, L., Näslund, M., \& Parling, T. (2016). Preliminary investigation of executive functions in 
elite ice hockey players. Journal of Clinical Sport Psychology, 10, 324-335.

Ma, I., Mies, G. W., Lambregts-Rommelse, N. N. J., Buitelaar, J. K., Cillessen, A. H. N., \& Scheres, A. (2018). Does an attention bias to appetitive and aversive words modulate interference control in youth with ADHD? Child Neuropsychology, 24, 541-557.

Marchetti, R., Forte, R., Borzacchini, M., Vazou, S., Tomporowski, P. T., \& Pesce, C. (2015). Physical and motor fitness, sport skills and executive function in adolescents: A moderated prediction model. Psychology, 6, 1915-1929.

Martin, A., Booth, J. N., Laird, Y., Sproule, J., Reilly, J. J., \& Saunders, D. H. (2018). Physical activity, diet and other behavioural interventions for improving cognition and school achievement in children and adolescents with obesity or overweight. Cochrane Database of Systematic Reviews, 2018, CD009728.

Pesce, C. (2012). Shifting the focus from quantitative to qualitative exercise characteristics in exercise and cognition research. Journal of Sport and Exercise Psychology, 34, 766-786.

Plháková, A. (2003). Učebnice obecné psychologie [General psychology textbook]. Prague, Czech Republic: Academia. Scudder, M. R., Lambourne, K., Drollette, E. S., Herrmann, S. D., Washburn, R. A., Donnelly, J. E., \& Hillman,
C. H. (2014). Aerobic capacity and cognitive control in elementary school-age children. Medicine \& Science in Sports \& Exercise, 46, 1025-1035.

Šlédr, J. (2000). Psychologický slovník trenéra [Psychological vocabulary of a trainer]. Tenis, 11(5), 22.

Stroop, J. R. (1935). Studies of interference in serial verbal reactions. Journal of Experimental Psychology, 18, 643-662.

Vágnerová, M. (2005). Vývojová psychologie I.: Dětství a dospívání [Developmental psychology I.: Childhood and adolescence]. Prague, Czech Republic: Karolinum.

Vařeková, J., \& Dad’ová, K. (2014). Pohybová aktivita a kognitivní funkce [Physical activity and cognitive functions]. Medicina Sportiva Bohemica et Slovaca, 23, 210-215.

Vestberg, T., Gustafson, R., Maurex, L., Ingvar, M., \& Petrovic, P. (2012). Executive functions predict the success of top-soccer players. PLoS ONE, 7(4), e34731.

Voss, M. W., Kramer, A. F., Basak, C., Prakash, R. S., \& Roberts, B. (2010). Are expert athletes 'expert' in the cognitive laboratory? A meta-analytic review of cognition and sport expertise. Applied Cognitive Psychology, 24, 812-826.

Ward, J. (2006). The student's guide to cognitive neuroscience. London, United Kingdom: Psychology Press.

Weiner, I., Lerner, R. M., Easterbrooks, M. A., \& Mistry, J. (2003). Handbook of psychology: Developmental psychology. Hoboken, NJ: Willey. 